Article

\title{
Performance Simulation and Benefit Analysis of Ammonia Absorption Cooling and Heating Dual-Supply System Based on Off-Peak Electricity Heat Storage
}

\author{
Shaowu Yin ${ }^{1,2, *}$, Yongle Shi ${ }^{1}$, Lige Tong ${ }^{1,2}$, Li Wang ${ }^{1,2}$ and Yulong Ding ${ }^{3}$ \\ 1 School of Energy and Environmental Engineering, University of Science and Technology Beijing, \\ Beijing 100083, China; shiyongle@xs.ustb.edu.cn (Y.S.); tonglige@me.ustb.edu.cn (L.T.); \\ liwang@me.ustb.edu.cn (L.W.) \\ 2 Beijing Key Laboratory of Energy Saving and Emission Reduction in Metallurgical Industry, \\ University of Science and Technology Beijing, Beijing 100083, China \\ 3 College of Chemical Engineering, University of Birmingham, Birmingham B15 2TT, UK; Y.Ding@bham.ac.uk \\ * Correspondence: yinsw@ustb.edu.cn
}

Received: 16 May 2019; Accepted: 14 June 2019; Published: 16 June 2019

check for updates

\begin{abstract}
The energy consumption of urban central heating in northern China is two to four times that in northern Europe and other countries. Beijing has adopted measures, such as 'coal to gas' and 'coal to electricity', to reduce environmental pollution caused by central heating. Given a peak-to-valley difference in the electricity supply of power plant, which is uneven day and night, this study proposes to store the night-time off-peak electricity in the form of heat energy and drive the ammonia absorption system in the form of steam or hot water during peak or flat electricity. Simulation results of ammonia absorption cooling and heating dual-supply system show that heat source temperature increases, evaporation temperature increases, and cooling water temperature decreases are all beneficial to improve the refrigeration coefficient in the summer cooling condition. In the meantime, heat source temperature increases, evaporation temperature increases, and cooling water temperature decreases are beneficial for increasing the heating coefficient in the winter heating condition. The heating and cooling coefficients of the system are 1.38 and 0.65 in the optimal working condition in winter and summer. Benefit analysis shows that, compared with central heating and cold storage air conditioning, the system can save 576,000 tons of standard coal and 1.417 million tons of carbon dioxide if used in $12 \%$ of the cooling and heat supply areas in Beijing. The potential for energy saving and emission reduction is large.
\end{abstract}

Keywords: energy storage; performance simulation; off-peak electricity; energy conservation

\section{Introduction}

In recent years, given the continuous development in Chinese construction industry, building energy consumption accounts for more than a quarter of the total energy consumption in China [1]. Heating and cooling are the main components of building energy consumption. The energy consumption of urban central heating in northern China is two to four times that in northern European countries [2]. Beijing has taken measures to move energy consumption from coal to gas and electricity to reduce environmental pollution caused by central heating. However, for China's 'rich coal, lean oil, less gas' energy storage and supply status, replacing coal with natural gas for heating is not a long-term solution. Urban heating has the following problems: The average winter heating efficiency of China's coal-fired boilers is approximately 0.6 [3], and the central heating is under the pressure 
of multiple problems, such as low efficiency, high energy consumption, and serious environmental pollution $[4,5]$. In recent years, the valley difference in China's power grid peaks has increased annually. Electricity use for cooling and heating has the problem of insufficient power supply during peak hours. Given a peak-to-valley difference in the electricity supply of power plant, which is uneven day and night, this paper proposes, for the first time, to store the night-time off-peak electricity in the form of heat energy and drive the ammonia water absorption system in the form of steam or hot water during peak or flat electricity periods, to realize the functions of cooling in summer and heating in winter.

At present, many scholars are studying the cooling and heating system on the basis of off-peak electricity. A number of research options such as various types of absorption refrigeration systems, research on working fluids, and improvement of absorption processes are discussed [6]. Li et al. studied a hybrid heating system that combines solar energy with low-cost valley power using a phase change heat storage device [7]. Combined with grid time-sharing pricing, solar energy supply, off-peak electricity, and building thermal load are matched in time domain. Wu et al. studied an off-peak electricity heating system, using abandoned wind, abandon photoelectric, or off-peak electricity to heat low-temperature molten salt and store energy to meet heating requirements [8]. Zhu et al. introduced an example of a solar low-grid electric relay heating project in Beijing, introduced the design scheme and principle of the project and analysed and calculated the heating system data. These data have referential importance for the selection of heating design parameters of the current building in Beijing and the optimal design of solar off-peak electricity relay heating system [9]. Keinath et al. established a model for ammonia absorption heat pump heating for residential applications and introduced a direct gas single-effect ammonia absorption heat pump water heater for residential applications [10]. Jiang et al. proposed a system that uses the principle of ammonia absorption heat pump to absorb heat from the solution in the absorber to absorb heat and uses ammonia water with different mass fractions as an energy carrier to achieve energy transport without heat loss at ambient temperature [11]. Given that the system uses latent heat for heating, the pump power consumption is greatly decreased. In order to use the low-temperature ambient air in winter as a low-temperature heat source for a heat pump system, Liu et al. studied the performance simulation of a single-stage ammonia absorption heat pump and analysed the effects of occurrence, absorption, and rectification temperatures on the heating performance of the system [12]. Xue et al. comprehensively studied the ammonia absorption refrigeration process by using Aspen Plus software to simulate this process and explored the impact of the absorber operating pressure on the outlet ammonia concentration and liquid ammonia evaporation temperature [13].

On the basis of the above-mentioned research, this study proposes an ammonia absorption cooling and heating dual-supply system (AACHDSS) based on off-peak electricity heat storage (OPEHS). The system consists of an off-peak electricity heat storage device and an ammonia absorption system. The night-time off-peak electricity is stored in the form of heat energy, and the ammonia absorption system is driven by steam or hot water during the peak or flat electricity period for summer cooling, winter heating, and supplying domestic hot water. The system can increase the use of off-peak electricity and the power generation efficiency of power plants and promote clean heating technology [14,15], which can be used as a supplement to the existing heating and cooling methods.

\section{System Design}

The AACHDSS based on off-peak electricity heat storage is composed of a heat storage device, a generator, an absorber, a condenser, a terminal heat exchange system and a control system, as shown in Figure 1a. The off-peak electricity is stored in the form of heat energy in the electric energy storage device, and the stored heat is converted into steam to drive ammonia absorption refrigeration system when necessary to achieve summer cooling and winter heating. 


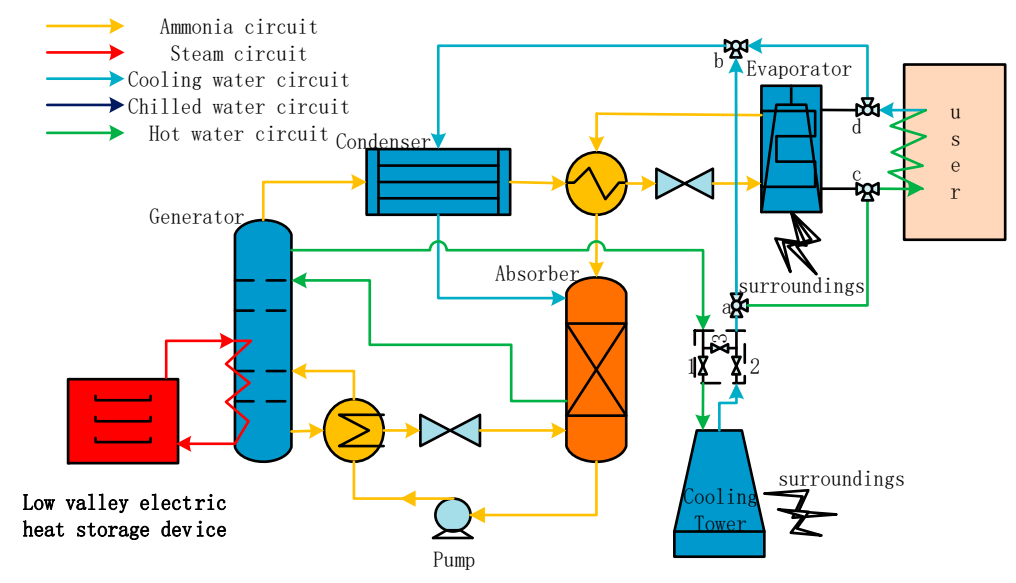

(a)

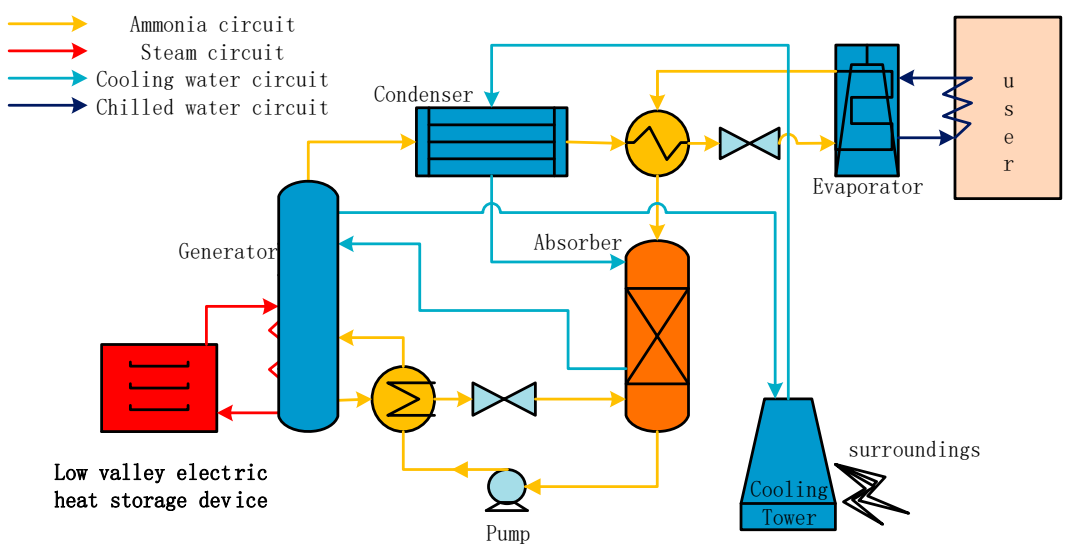

(b)

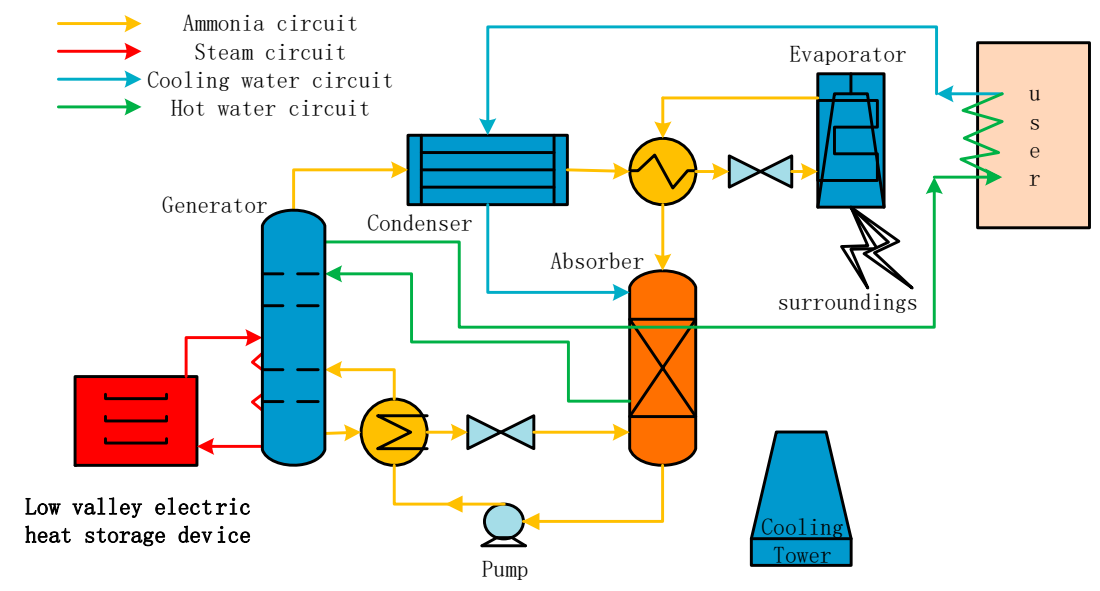

(c)

Figure 1. (a) Schematic of ammonia absorption cooling and heating dual-supply system (AACHDSS) based on off-peak electricity heat storage. (b) Schematic of AACHDSS based on off-peak electricity heat storage in summer. (c) Schematic of AACHDSS based on off-peak electricity heat storage in winter. 
The model of ammonia absorption system is established, and the performance of summer cooling and winter heating of the system is simulated. The influences of parameters such as heat source, evaporation, and cooling water temperatures on system coefficient of performance are analyzed, and the optimal working conditions are proposed.

In the summer, the system stores electricity in the form of heat energy in the heat storage device at night and converts the stored energy into a high-temperature steam to drive the generator of the ammonia absorption refrigeration system when needed. The ammonia water-concentrated solution is separated into a diluted ammonia solution and water-containing ammonia. After passing through the rectification column, the water-containing ammonia is cooled from the top of the column into the condenser and cooled to an ammonia solution. After heat exchange occurs in the solution heat exchanger, the throttling and depressurization become a low-temperature vapor-liquid mixture and then enters the evaporator to absorb heat. As a result, the cooling capacity can be obtained.

The winter system stores electricity in the form of heat energy in the energy storage device at night and uses high-temperature steam to drive the absorption heat pump when needed. Cooling water flows through the condenser and absorber to absorb heat. Then, the cooling water that flows through the cooling tower is switched to the user side by adjustment. The evaporator converts to air-cooled evaporation to absorb heat from the environment.

The cooling and heating coefficients are used to evaluate the performance of the AACHDSS based on off-peak electricity heat storage. The calculation formula is shown as follows.

Refrigeration coefficient:

$$
E E R=\frac{Q_{E}}{W_{0}}
$$

$Q_{E}$ is the evaporator cooling capacity, $\mathrm{W}$;

$W_{0}$ is the power consumption, $\mathrm{W}$;

Heating coefficient:

$$
C O P=\frac{Q_{C}}{W_{0}} .
$$

$Q_{C}$ is the total heat release amount flowing through the component, $\mathrm{W}$;

$W_{0}$ is the power consumption, $\mathrm{W}$.

\section{Performance Simulation and Result Analysis}

Aspen Plus software is used to simulate the single-stage ammonia absorption system and analyze the operating characteristics of the system in winter and summer to obtain the variation in the performance coefficient of the ammonia absorption system under refrigeration and heating conditions [16]. When satisfying heating and cooling conditions, the change rule of system performance coefficient of the cooling and heating dual-supply system under different heat source, evaporation, and condensation temperatures and other conditions are obtained. Accordingly, the optimal operating conditions of the off-peak electricity energy storage device and the ammonia absorption system are obtained.

The user area of $100 \mathrm{~m}^{2}$ is used as an example to simulate the two conditions of summer cooling and winter heating. The heat and cold load [17] values are 100 and $58 \mathrm{~W} / \mathrm{m}^{2}$.

\subsection{Summer Cooling Conditions}

To ensure the normal operation of the system, the ammonia absorption system requires the heat source temperature to be higher than $110^{\circ} \mathrm{C}$ in the summer cooling. When the heat source is raised from $110^{\circ} \mathrm{C}$ to $130{ }^{\circ} \mathrm{C}$, the refrigeration coefficient is increased from 0.42 to 0.61 . As the heat source temperature increases, the distillation capacity and the ability of the rectification tower to provide ammonia are improved. The same concentration of aqueous ammonia enters the system when the heat source temperature is high, the concentration of the dilute solution is small, and the absorption capacity is strong. The cooling coefficient is unchanged from $130^{\circ} \mathrm{C}$ to $160^{\circ} \mathrm{C}$. The heat loss is large when the 
temperature is higher than $160^{\circ} \mathrm{C}$, and the refrigeration coefficient has a downward trend, as shown in Figure 2. When the temperature of the cooling water is high $\left(T_{w}=34^{\circ} \mathrm{C}\right)$, the cooling coefficient of the system is low with an average of approximately 0.6 under the same heat source, and the cooling water outlet temperature is approximately $46^{\circ} \mathrm{C}$, which can provide users with domestic hot water. When the temperature of the cooling water changes, the cooling water is decreased from $34{ }^{\circ} \mathrm{C}$ to $17^{\circ} \mathrm{C}$ and the cooling coefficient is increased from 0.61 to 0.7 . This condition reduces the system's requirements on the heat source temperature and improves the utilization range of steam and high-temperature water. Therefore, in this case, low-temperature cooling water should be used to maintain a high cooling coefficient and to expand the system's requirements for heat source temperature.

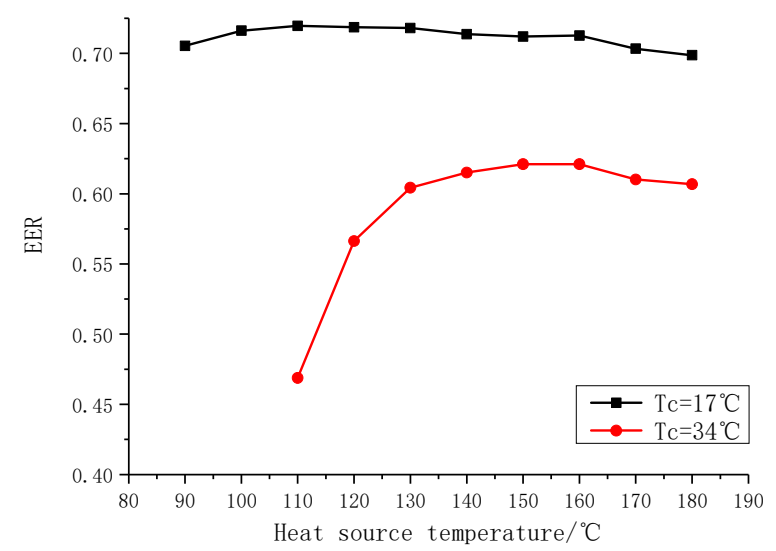

Figure 2. Effect of heat source and cooling water temperatures $\left(T_{\mathcal{C}}\right)$ on system performance.

When the temperature of the heat source is substantially constant, the change in the evaporation temperature of the ammonia absorption system also affects the refrigeration coefficient of the system. Figure 3 shows that when the temperature of the heat source is $120^{\circ} \mathrm{C}$, the temperature of the cooling water is $34^{\circ} \mathrm{C}$. When the evaporation temperature is increased from $2{ }^{\circ} \mathrm{C}$ to $7{ }^{\circ} \mathrm{C}$, the refrigeration coefficient is increased from 0.47 to 0.57 .

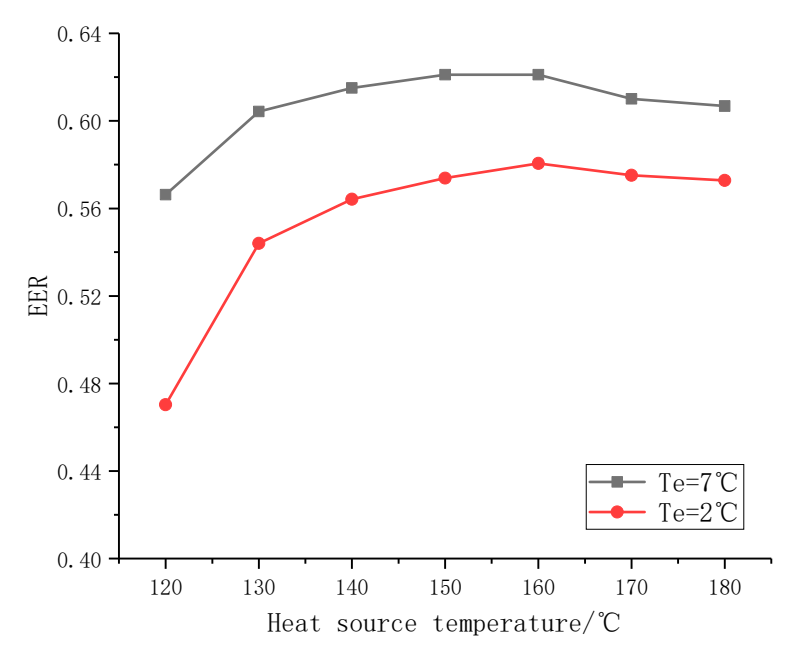

Figure 3. Effect of heat source and evaporation temperatures $\left(T_{e}\right)$ on system performance.

As the temperature of the heat source increases, the refrigeration coefficient of the system tends to be stable. As the evaporation temperature decreases, the evaporation pressure of the system, the absorption pressure, and the absorption capacity decrease. The concentration of the concentrated solution at the outlet is also decreased. The same amount of pure ammonia vapor is separated, and the flow rate of the concentrated solution entering the separator is increased. This condition increases the generator load. The refrigeration coefficient of the system is lowered under the same heat source and 
condensation temperature conditions. Therefore, the evaporation temperature should be increased as much as possible within the allowable range.

\subsection{Winter Heating Conditions}

In winter, the evaporator uses air cooling to take heat from the environment. In accordance with the average temperature of the heating season in Beijing, the heat and cooling dual-supply system has an evaporation temperature of approximately $-10^{\circ} \mathrm{C}$ in three-quarters of the heating season, and the temperature is around $-3^{\circ} \mathrm{C}$ in other times.

The simulation result (Figure 4) shows that when the evaporation temperature is $-10^{\circ} \mathrm{C}$, the heat source temperature rises from $130{ }^{\circ} \mathrm{C}$ to $160^{\circ} \mathrm{C}$ and the heat supply coefficient increases from 1.34 to 1.39 . The increase in heat source temperature enhances the ability of the distillation column to separate pure ammonia. The concentration of the dilute solution is decreased, and the cycle coefficient is increased. As a result, the heating coefficient increases. The heat source temperature continues to rise, and the heating coefficient is unchanged.

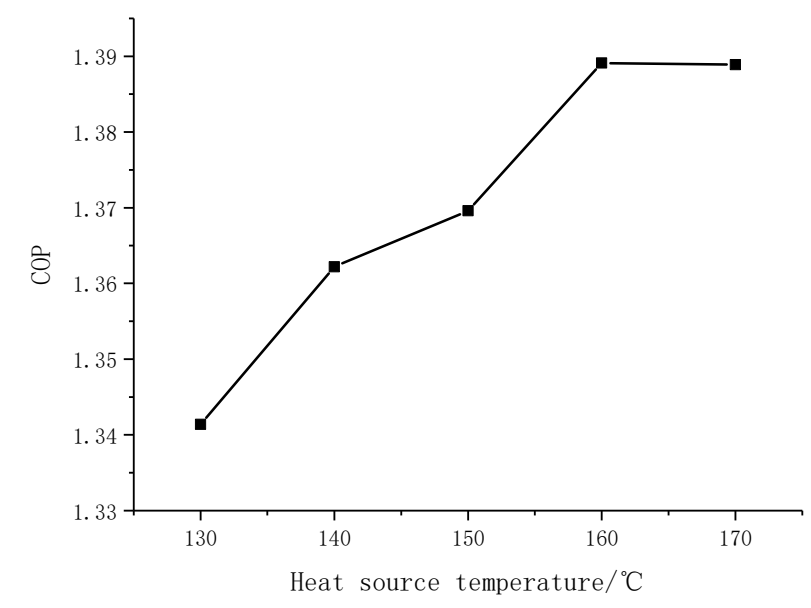

Figure 4. Effect of heat source temperature on system performance.

Figure 5 shows that, at the same heat source and condensation temperature, the heating coefficient is increased from 1.37 to 1.44 when the evaporation temperature is increased from $-10^{\circ} \mathrm{C}$ to $-3{ }^{\circ} \mathrm{C}$. In consideration of the average winter temperature in Beijing, the average heating coefficient is 1.39 . When the cooling water temperature is raised from $34^{\circ} \mathrm{C}$ to $38^{\circ} \mathrm{C}$, as shown in Figure 6, the heating coefficient is decreased from 1.44 to 1.41. As the cooling water temperature increases, the absorption effect deteriorates, and the heating coefficient decreases continuously. At the same time, the system can provide users with hot water of $48-60^{\circ} \mathrm{C}$ (Figure 7).

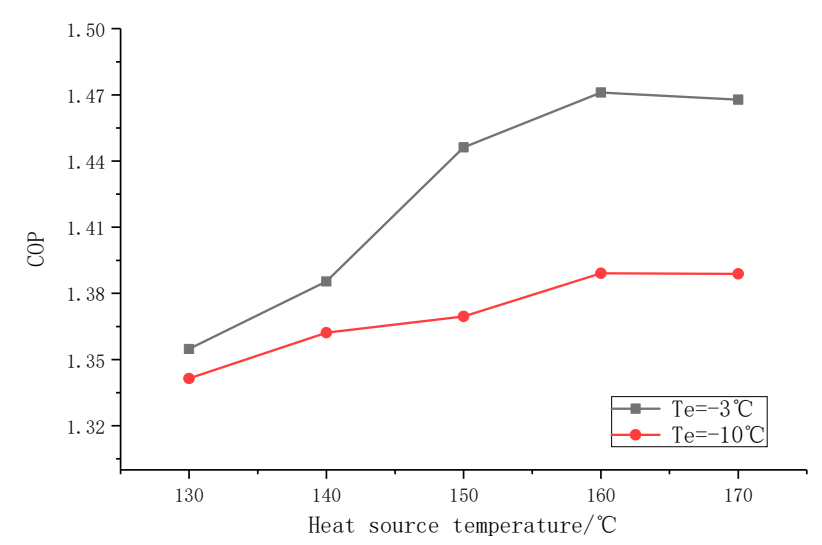

Figure 5. Effect of heat source and evaporation temperatures $\left(T_{e}\right)$ on system performance. 


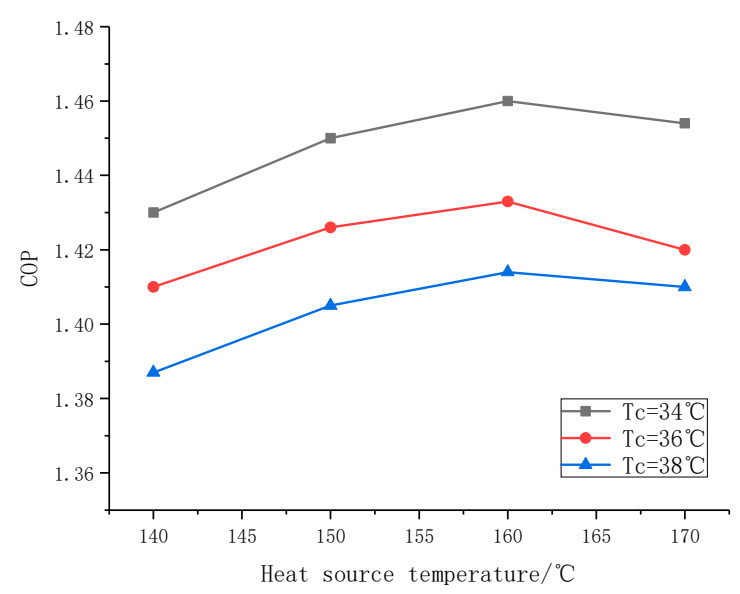

Figure 6. Effect of heat source and cooling water temperatures $\left(T_{\mathcal{c}}\right)$ on system performance.

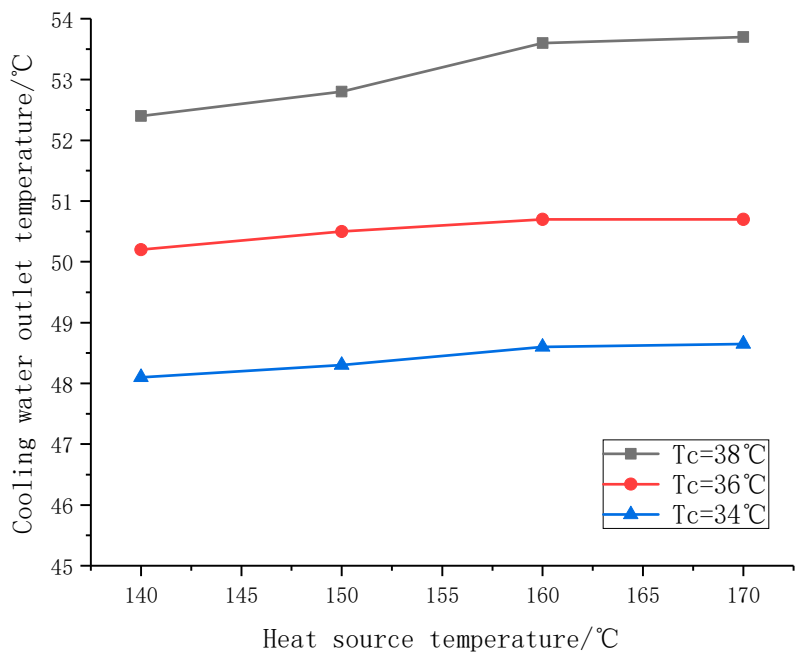

Figure 7. Effect of heat source and cooling water temperatures $\left(T_{c}\right)$ on cooling water outlet temperature.

\subsection{Optimal Condition}

Considering factors, such as heat loss, the optimum cooling coefficient is approximately 0.65 in summer when the heat source temperature is $150^{\circ} \mathrm{C}$, the cooling water temperature is $17^{\circ} \mathrm{C}$, and the evaporation temperature is $7{ }^{\circ} \mathrm{C}$. Under the heating conditions in winter, the heat source temperature is $160{ }^{\circ} \mathrm{C}$, the cooling water temperature is $36{ }^{\circ} \mathrm{C}$, the evaporation temperature is $-10{ }^{\circ} \mathrm{C}$, and the optimum heating coefficient is approximately 1.38 .

\section{Benefit Analysis}

The energy saving and emission reduction effects of this system are analyzed by comparing the annual energy consumption of the AACHDSS based on off-peak electricity heat storage with the annual primary energy consumption of the coal-fired boiler centralized heating combined with an ice storage air-conditioning system. The power consumption for cooling and heating of the dual-supply system is all provided by off-peak electricity to simplify the calculation. The cooling power consumption of an ice storage air conditioning in summer is also provided by off-peak electricity, whereas the central heating in winter is provided by coal-fired boilers [18].

Table 1 shows the energy consumption and efficiency parameters of central heating and coal-fired boilers in the dual-supply system in winter. Table 2 shows the energy consumption and efficiency parameters of dual-supply and ice storage air conditioning in summer. The calorific value of the standard coal is $29,307 \mathrm{~kJ} / \mathrm{kg}$; that is, the calorific value $q$ is $8.14 \mathrm{kWh} / \mathrm{kg}$, and the coal power generation efficiency [19] $\eta_{\mathrm{cp}}$ is 0.383 . 
Table 1. Winter heating energy consumption and cost parameters [20].

\begin{tabular}{ccc}
\hline Name & Central Heating of Coal-Fired Boilers & Dual-Supply Heating \\
\hline Central heating boiler efficiency $\eta_{2}$ & 0.6 & 1 \\
Network management efficiency $\eta_{3}$ & 0.68 & 1 \\
Heating coefficient COP & - & 1.38 \\
Coal power generation efficiency $\eta_{c p}$ & - & $\eta_{c p}$ \\
Unit heat consumption $p / \mathrm{kWh}$ & - & $C O P^{-1} \cdot \eta_{1}^{-1}$ \\
Primary energy consumption $e / \mathrm{kg}$ & $\eta_{2}^{-1} \cdot \eta_{3}^{-1} \cdot q^{-1}$ & $p \cdot \eta_{c p}^{-1} \cdot q^{-1}$ \\
\hline
\end{tabular}

Table 2. Summer cooling energy consumption and cost parameters [21].

\begin{tabular}{ccc}
\hline Name & Ice Storage Air Conditioning & Dual-Supply Cooling \\
\hline Energy Efficiency Ratio EER & 2.7 & 0.65 \\
Coal power generation efficiency $\eta_{c p}$ & $\eta_{c p}$ & $\eta_{c p}$ \\
Unit cooling power consumption $p / \mathrm{kWh}$ & $E E R^{-1}$ & $E E^{-1} \cdot \eta_{1}{ }^{-1}$ \\
Primary energy consumption $e / \mathrm{kg}$ & $p \cdot \eta_{c p}^{-1} \cdot q^{-1}$ & $p \cdot \eta_{c p}^{-1} \cdot q^{-1}$ \\
\hline
\end{tabular}

Boiler central heating cannot achieve on-demand heating, and the residential load rate $r_{j}=1$. The average heating load rate of the cooling and heating dual-supply system in winter [22] is 0.6, and the average cooling load rate in summer is 0.35 . The heating season time $t_{\mathrm{w}}$ is 120 days $(24 \mathrm{~h} / \mathrm{d})$. The cooling season time $t_{\mathrm{s}}$ is 62 days $(24 \mathrm{~h} / \mathrm{d})$. The specific energy cost calculation is shown in Table 3.

Table 3. Energy consumption and cost calculation for different cooling and heating modes.

\begin{tabular}{ccccc}
\hline Name & Central Heating & $\begin{array}{c}\text { Ice Storage Air } \\
\text { Conditioning }\end{array}$ & $\begin{array}{c}\text { Dual-Supply } \\
\text { Heating }\end{array}$ & $\begin{array}{c}\text { Dual-Supply } \\
\text { Cooling }\end{array}$ \\
\hline Heat supply/cooling capacity $Q$ & $F \cdot f \cdot l \cdot t \cdot r_{j}$ & $F \cdot f \cdot l \cdot t \cdot r_{j}$ & $F \cdot f \cdot l \cdot t \cdot r_{j}$ & $F \cdot f \cdot l \cdot t \cdot r_{j}$ \\
$\left(r_{j}=1\right)$ & - & $\left(r_{j}=0.35\right)$ & $\left(r_{j}=0.6\right)$ & $\left(r_{j}=0.35\right)$ \\
Filling valley electricity $P$ & $E=Q \cdot e$ & $E \cdot E E R^{-1} \cdot \eta_{1}{ }^{-1}$ & $P=Q \cdot C O P^{-1} \cdot \eta_{1}{ }^{-1}$ & $P=Q \cdot E E R^{-1} \cdot \eta_{1}{ }^{-1}$ \\
Primary energy consumption $E$ & $E=Q \cdot e$ & $E=Q \cdot e$ & $E=Q \cdot e$ \\
\hline
\end{tabular}

In Table 3, $F$ is the cold and heat supply area of Beijing in 2017. $f$ is the application area of AACHDSS based on off-peak electricity heat storage. $l$ is the refrigeration and heating load. $t$ is the time for refrigeration and heating. $\eta_{1}$ is the electrothermal conversion efficiency of the heat storage. $\eta_{1}=0.975$.

From Tables 1-3, the annual primary energy consumption of centralized heating combined with an ice storage air-conditioning system and the cooling and heating dual-supply system at different application area ratios are obtained, as shown in Figure 8.

In 2017, the hot and cold supply area of Beijing $F$ is approximately 908 million $\mathrm{m}^{2}$. Assuming that $12 \%$ of the hot and cold supply area uses the AACHDSS based on off-peak electricity heat storage, the annual energy consumption is 5.578 million tons of standard coal. Compared with the centralized heating combined with an ice storage air-conditioning system, AACHDSS can save 576,000 tons of standard coal and obtain an energy saving rate of $9.4 \%$. If the standard price of standard coal is $\$ 124.1 /$ ton, then energy cost savings is approximately $\$ 71.5$ million, and $\mathrm{CO}_{2}$ emissions are decreased by 1.417 million tons. The potential for energy saving and emission reduction is large. 


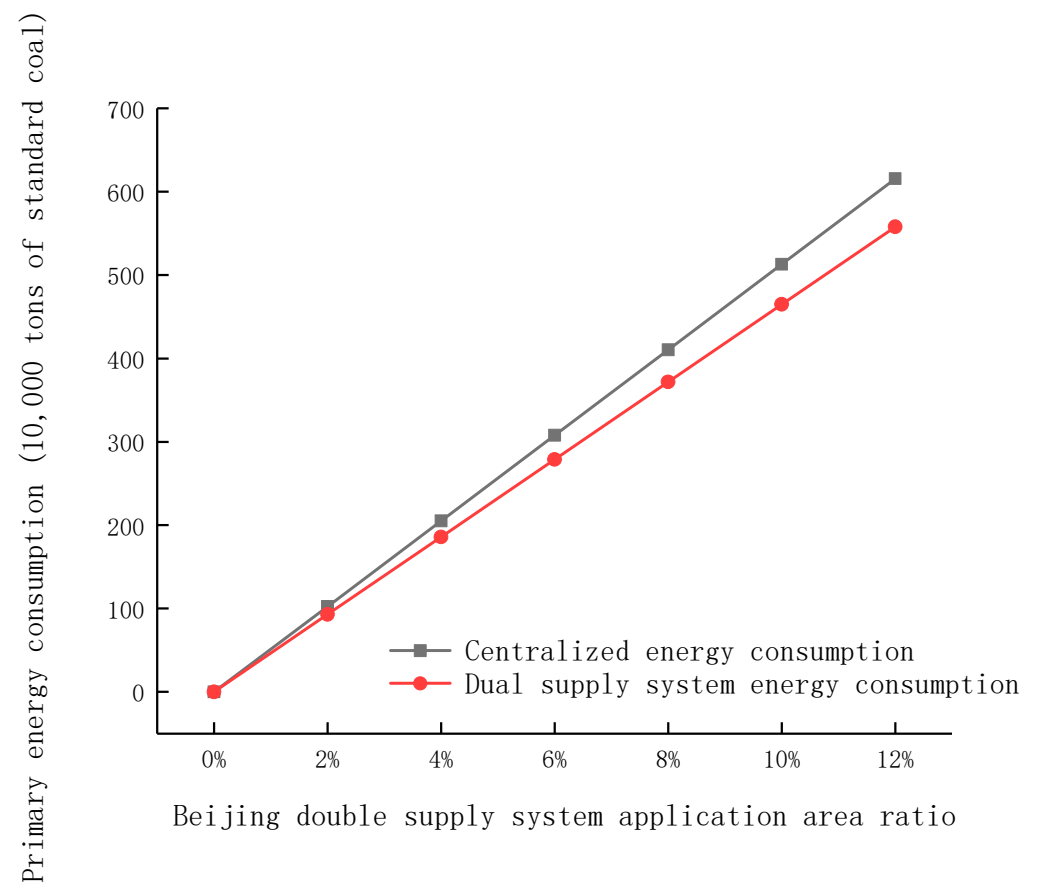

Figure 8. Relationship between application ratio of different energy supply system and primary energy consumption.

\section{Conclusions}

From the simulation and analysis, the following conclusions are drawn.

(1) In summer cooling, when the heat source rises from $110{ }^{\circ} \mathrm{C}$ to $130{ }^{\circ} \mathrm{C}$, the refrigeration coefficient increases from 0.42 to 0.61 , the cooling coefficient of $130{ }^{\circ} \mathrm{C}$ to $160^{\circ} \mathrm{C}$ is basically unchanged, and the cooling coefficient has a downward trend when the temperature is above $160^{\circ} \mathrm{C}$. At a heat source temperature of $120^{\circ} \mathrm{C}$, when the evaporation temperature is increased from $2{ }^{\circ} \mathrm{C}$ to $7{ }^{\circ} \mathrm{C}$, the refrigeration coefficient is increased from 0.47 to 0.57 . The cooling water is lowered from $34^{\circ} \mathrm{C}$ to $17^{\circ} \mathrm{C}$, and the refrigeration coefficient is increased from 0.61 to 0.7 .

(2) When heating in winter, the heat source temperature rises from $130^{\circ} \mathrm{C}$ to $160^{\circ} \mathrm{C}$, the heat supply coefficient rises from 1.34 to 1.39 , the heat source temperature continues to rise, and the heat supply coefficient is basically unchanged. The heating coefficient increases from 1.37 to 1.44 when evaporation temperature is raised from $-10{ }^{\circ} \mathrm{C}$ to $-3{ }^{\circ} \mathrm{C}$ under the same heat source and condensing temperature conditions. When the cooling water temperature rises from $34^{\circ} \mathrm{C}$ to $38^{\circ} \mathrm{C}$, the heating coefficient decreases from 1.44 to 1.41. Combined with the cooling water temperature rising, the absorption effect is deteriorated, the heating coefficient is continuously decreased, and the system can provide the user with hot water of $48^{\circ} \mathrm{C}-60^{\circ} \mathrm{C}$.

(3) Considering factors such as heat loss, the optimum cooling coefficient is approximately 0.65 in summer when the heat source temperature is $150^{\circ} \mathrm{C}$, the cooling water temperature is $17^{\circ} \mathrm{C}$, and the evaporation temperature is $7{ }^{\circ} \mathrm{C}$. Under the heating conditions in winter, the heat source temperature is $160{ }^{\circ} \mathrm{C}$, the cooling water temperature is $36{ }^{\circ} \mathrm{C}$, the evaporation temperature is $-10^{\circ} \mathrm{C}$, and the optimum heating coefficient is approximately 1.38 .

(4) If $12 \%$ of the hot and cold supply area in Beijing uses the AACHDSS based on off-peak electricity heat storage, then the system can realize annual standard coal saving of 576,000 tons, energy cost savings of $\$ 71.5$ million and hydrogen dioxide emission reductions of 1.417 million tons compared with the centralized heating combined with an ice storage air-conditioning system based on 2017 statistics. The potential for energy saving and emission reduction is large.

Compared with the coal-fired central heating combined with an ice storage air-conditioning system, the AACHDSS based on off-peak electricity heat storage occupies small space, requires a 
small initial investment, and can realize noiseless operation. Although the refrigeration coefficient is low, it has advantages such as simple structure, easy operation, and little pollution. The system can also increase heating capacity in winter, improve equipment utilization and system operation cycle, and effectively respond to energy saving and emission reduction call whilst considering the balance of grid load. AACHDSS can be suitably applied in rural areas, suburbs, and other decentralized cooling and heating applications.

Author Contributions: S.Y. and Y.S. designed the manuscript; Y.S. and S.Y. drafted the manuscript; S.Y., Y.S. and L.T. collected the data and revised the manuscript; L.W. and Y.D. checked the content and revised the manuscript. All authors made contributions to the study and the writing of the manuscript.

Funding: This research was funded by the National key research and development plan of China (Grant No. 2018YFB0605901).

Conflicts of Interest: The authors declare no conflict of interest.

\section{References}

1. Pérez-Lombard, L.; Ortiz, J.; Pout, C. A review on buildings energy consumption information. Energy Build. 2008, 40, 394-398. [CrossRef]

2. Shan, X.Z. Application Analysis of Energy-Saving Technologies and Measures in Central Heating Systems; Tianjin University: Tianjin, China, 2008.

3. Tsinghua University Building Energy Conservation Research Center. China Building Energy Efficiency Annual Development Research Report; China Building Industry Press: Beijing, China, 2011.

4. Zhang, Q.; Zhang, L.; Nie, J.; Li, Y. Techno-Economic analysis of air source heat pump applied for space heating in northern China. Appl. Energy 2017, 207, 533-542. [CrossRef]

5. Cai, W.G.; Wu, Y.; Zhong, Y.; Ren, H. China building energy consumption: Situation, challenges and corresponding measures. Energy Policy 2009, 37, 2054-2059. [CrossRef]

6. Srikhirin, P.; Aphornratana, S.; Chungpaibulpatana, S. A review of absorption refrigeration technologies. Renew. Sustain. Energy Rev. 2011, 5, 343-372. [CrossRef]

7. Li, L.X.; Zhang, L.; Wu, P. A Hybrid Heating System Based on Solar Energy and off-peak electricity. Wall Mater. Innov. Build. Energy Effic. 2010, 44-46.

8. Wu, Y.T.; Zhang, X.M.; Wang, H.F.; Sun, J.Q. Technology and Evaluation of molten Salt Regenerative heating based on abandoned Wind and Light or low current Electric heating. Chin. Foreign Energy 2017, 2.

9. Zhu, C.H.; Li, B.G.; Su, S.Q. Example of solar valley electric relay heating engineering in a company in Beijing. Build. Energy Sav. 2016, 44.

10. Keinath, C.M.; Garimella, S.; Garrabrant, M.A. Modeling of an ammonia-water absorption heat pump water heater for residential applications. Int. J. Refrig. 2017, 83, 39-50. [CrossRef]

11. Jiang, S.L.; Cheng, W.L.; Zhao, R.; Chen, Z.S. Study on Heat pump heating system without Heat loss. HVAC 2007, 37, 66-69.

12. Liu, Y.; Yuan, W.; Guo, B.H. Performance Simulation of Ammonia Absorption Heat Pump Type I. In Proceedings of the Annual meeting of China Refrigeration Society, Shanghai, China, 7-9 April 2011.

13. Xue, L.; Pan, Z.; Hao, X. Simulation of ammonia absorption Refrigeration process based on Aspen Plus. Shandong Chem. Ind. 2013, 42, 112-113.

14. $\mathrm{Xu}, \mathrm{J}$. The present situation of coal power conversion in Beijing suburbs and the suggested direction of work. HVAC 2015, E12, 20-22.

15. Zhang, H.; Baeyens, J.; Cáceres, G.; Degreve, J.; Lv, Y. Thermal energy storage: Recent developments and practical aspects. Prog. Energy Combust. Sci. 2016, 53, 1-40. [CrossRef]

16. Li, Y.C. The Simulation of Ammonia-water Absorption Refrigeration System. Chongqing University 2016, $38-47$.

17. Ministry of Housing and Urban-Rural Development of the People's Republic of China. GB50736-2012, Code for Design of Heating, Ventilation and Air Conditioning for Civil. Buildings; China Construction Industry Press: Bejing, China, 2012.

18. Su, C.; Madani, H.; Palm, B. Building heating solutions in China: A spatial techno-economic and environmental analysis. Energy Convers. Manag. 2019, 179, 201-218. [CrossRef] 
19. Xu, N.; Li, H.R.; Zhu, Y.D.; Lei, J.J. On the functional relationship between Energy use efficiency and Energy consumption Indexes in Coal-fired Power plants. Energy Energy Sav. 2017, 84-85.

20. Wei, B.; Li, L. The present situation of Heat supply Network in China and the Countermeasures of heating Energy Saving. Refrig. Air Cond. (Sichuan) 2008, 22, 28-30.

21. Fang, G.; Liu, X. Exergy analysis of ice storage air-conditioning system with heat pipe during charging period. Energy Sustain. Dev. 2010, 14, 149-153. [CrossRef]

22. Han, Y.R. Energy Saving measures for heating and Air-conditioning system. New Technol. New Prod. Chin. 2010, 4, 79 . 